\title{
BELLO, Walden. Food Wars - Crisis alimentaria y políticas de ajuste estructural. Virus editorial, Bilbao: 2012. Traduc- ción del inglés por Ambar Sewell.
}

Walden Bello autor del libro Food Wars, originalmente escrito en inglés, es Filipino, es actualmente profesor de sociología en la State University of New York en Binghamton y investigador principal del Centro de Estudios del Sudeste Asiático de la Universidad de Kyoto en Japón. Fue miembro de la Cámara de Representantes de Filipinas de 2009 a 2015, durante la cual fue presidente del Comité de Asuntos de Trabajadores de Ultramar, como representante del partido de izquierda Akbayan. Es investigador y activista a través de sus escritos antiglobalización y en defensa de los derechos humanos.

Este libro se incluye en el rol de lecturas esenciales para las personas que buscan conocimientos acerca de la actual situación alimentaria mundial y cuales las consecuencias para los pueblos. El libro aborda la "evolución" de los sistemas agroalimentarios, sus actuales configuraciones y como han culminado en la gran crisis alimentaria de 2007-08. Bello estructuró su libro en siete capítulos, además de una introducción bien completa acerca de los antecedentes y asuntos relacionados al foco del libro y un epílogo hecho por otro autor, Tom Kucharz, miembro del grupo Ecologistas en Acción.

Como primera parte, la introducción presenta datos relativos al aumento de los precios de los alimentos, principalmente los alimentos considerados de consumo básico, tales como arroz y trigo, como ese factor evolucionó para la gran crisis de alimentos de 2007-08, así cómo fueran generados diversas protestas globales contra la subida incontrolada de los precios de productos de primera necesidad. En esa parte, Bello también ha hecho una crítica a la forma como se han pensado las causas de la crisis y las soluciones para la misma. La crítica se dirige a los análisis que argumentaban que la oferta de alimentos disminuya porque no había promoción de una agricultura comercial, especialmente en África, la prohibición del uso de organismos genéticamente modificados por la Unión Europea, y la creciente producción de agrocombustíbles, que desviaba un tercio de la producción de granos en los EEUU, por ejemplo. O sea, el aumento de la producción de alimentos, sea por la incorporación de técnicas genéticas o por eficiencia productiva, llevaría a una posible solución de la crisis. Y, el autor, por otro lado, rebate todos esos argumentos, demostrando las consecuencias de la utilización de OGM para la biodiversidad y la ineficacia de haber sólo el aumento de la producción sin adecuaciones en otros sectores productivos.

En el primero capítulo, el autor hace una trayectoria histórica acerca de la influencia del sistema capitalista sobre el campesinado. De acuerdo con Bello, la producción campesina de alimentos ha sido una forma de resistencia al capitalismo tradicional. La crisis de 2007-08 fue, según el autor, "una manifestación del que vendría a ser el último estadio del desplazamiento de la agricultura campesina por la agricultura capitalista" (p. 39). En ese capítulo, se demuestra la evolución de los sistemas agroalimentarios: el primero surgió a finales del siglo XIX bajo la influencia del Imperio Británico que llevaba al mundo los primeros valores de libre comercio; en seguida, ese primero sistema es sustituido por un sistema agroalimentario que adoptó los valores de Bretton Woods, al final de la Segunda Guerra Mundial, principalmente el comercio de alimentos por las grandes corporaciones; la fase actual, según Bello, hay un 
sistema agroalimentario mundial marcado por valores impuestos por la Organización Mundial del Comercio (OMC), "que promueve la expansión y hegemonía de la agricultura industrial corporativa a través de la institucionalización de las reglas del libre comercio y de los derechos de propiedad intelectual monopolísticos", así como el uso intensivo de técnicas de biotecnología. En todas esas fases, la agricultura campesina ha resistido como una forma alternativa y de más calidad de producir alimentos.

A partir del segundo capítulo, el autor empeza un análisis de las condiciones de los sistemas agrarios de algunos países y regiones del mundo, a saber, México, Filipinas, África y China. En el caso de México, la crisis en los precios de alimentos estaba conectada con otras crisis por las cuales el país ha pasado causadas principalmente por programas de ajustes estructurales promovidos por los organismos financieros internacionales y los E.E.U.U. La crisis alimentaria fue profundizada con la entrada en vigor del Tratado de Libre Comercio de América del Norte (NAFTA, en inglés) $y$, actualmente, México se encuentra en un nivel grave de inseguridad alimentaria, así como vive también en crisis económica y política, causadas sobre todo por las prácticas neoliberales de sus gobiernos. El segundo caso analizado es de su país de origen, Filipinas, donde la agricultura ha estado bajo los efectos del libre comercio en países en vías de desarrollo, especialmente la producción de arroz, producto fundamental nacionalmente. Antes uno dos mayores exportadores de ese producto, hoy Filipinas se ha transformado en el que más importa arroz para consumo de su población debido a la disminución de los importes gubernamentales en programas rurales inducida por mecanismos firmados por Manilla con organismos internacionales para el pago de la deuda externa y de ajustes de conducta con la entrada en la $\mathrm{OMC}$, como el término de las cuotas a las importaciones agrícolas.

El tercero caso analizado es la región africana. El continente africano es para Bello el caso más ilustrativo de cómo la base productiva de un continente entero puede ser afectado por políticas económicas doctrinarias. Una región que pasó de exportador nato de alimentos (décadas de 1960 hasta 1970) para un continente que vive fenómenos periódicos de hambre y hambrunas y hasta cuadros localizados de emergencias alimentarias, como en el cuerno de África, el Sahel, Sudáfrica y África central. La agricultura africana vive en crisis profunda, la cual es originada por múltiples causas, tales como las guerras civiles, la ampliación de enfermedades crónicas y también, como apunta el autor, explicada en gran medida por "la eliminación de los controles estatales y de los mecanismos de apoyo bajo los programas de ajuste estructural" para que la mayoría de los países africanos pudieran beneficiarse de las ayudas financieras del Banco Mundial y del Fondo Monetario Internacional para el pago de los intereses de la deuda externa. Y como un continente que importa alrededor de $25 \%$ dos alimentos que consume, África fue una de las protagonistas de la crisis de 2007-08 de aumento de los precios de los alimentos y sigue sufriendo sus efectos.

La agricultura china es el cuarto caso investigado por Bello en su libro. El autor apunta que, a pesar de la China ser identificada como el país que más contribuyó para el aumento de los precios de los alimentos, generando la crisis, por presión de su gran población, el país sólo importa pequeñas cantidades de arroz de primera calidad, pequeñas cantidades de trigo y no importa maíz, y mantuve su autosuficiencia en cereales hasta 2008.Sin embargo, China ha pasado por una reestructuración de su modelo agrario, subordinando su agricultura a la industrialización orientada a la explotación, los campesinos están migrando hacia las ciudades, provocando un déficit de mano de obra en el medio rural, hecho que tiene llevado la China a importar productos que antes producía, y también las crecientes exigencias de la OMC para 
admisión del país en su estructura que demandan que los chinos liberalicen sus reglas de comercio, principalmente del comercio agrícola.

Los dos últimos capítulos del libro de Walden Bello, son tratados los temas de la influencia de la producción de agrocombustíbles sobre el aumento de la inseguridad alimentaria en el mundo y la existencia de movimientos de resistencia a las imposiciones del sistema capitalista. En el capítulo seis, el autor argumenta que hay un link directo entre el aumento de las políticas impulsoras de los agrocombustíbles y el aumento de los precios de los alimentos en cerca de tres cuartos del aumento de $140 \%$ en E.E.U.U. y en la U.E. La principal justificativa es que los esfuerzos son desplazados desde la producción de alimentos (en general con precios menos atractivos en el mercado internacional) para la producción de insumos para crear los agrocombustíbles, provocando una oferta menor de alimentos en el mercado a un precio más alto. De acuerdo con el autor, aunque hubiera una promesa de la importancia de los agrocombustíbles para el desarrollo de los países del Sur y su producción no causaría daños al medio ambiente, el momento de ellos ha pasado y ya aparecen los efectos negativos del incremento de la producción para el medio ambiente y el aumento de los precios de los alimentos, véase la crisis de 2007-08.

En el séptimo capítulo, Bello nos trae un suspiro de esperanza y posibilidades positivas de resistencia y alternativas al capitalismo salvaje. El autor se utiliza de cuatro ejemplos para manifestar la importancia del movimiento internacional de campesinos y de pequeños agricultores como la fuente más dinámica de resistencia a la globalización impulsada por las grandes empresas. Se utiliza, por tanto, de los perfiles de Lee Kyung Hae, José Bové, João Pedro Stédile y el Movimiento de los Trabajadores Rurales Sin Tierra y La Vía Campesina. En el caso de La Vía Campesina, es un caso bastante ilustrativo también porque nos trae la discusión del concepto de soberanía alimentaria, el cual ha sido pensado como una alternativa al régimen agroalimentario actual. "El paradigma de la soberanía alimentaria supone un desafío (...) a los pilares de la agricultura industrial capitalista" (p. 215) incorporando temas como la autosuficiencia alimentaria, la agricultura no basada en el uso de pesticidas o en técnicas genéticas, el derecho de los pueblos de decidir sobre el qué, cómo y dónde producir, la propiedad agrícola familiar e igualitaria entre los géneros y los daños al medio ambiente. Bello finaliza su libro trayendo un tono de esperanza a los problemas relativos a la producción de alimentos por el mundo con la resistencia de los campesinos y de pequeños agricultores, que ofertan modelos alternativos para la sociedad. 